\title{
Prevalence of Intestinal Parasites at a Tertiary Care Centre at Dehradun, Uttarakhand, India
}

\author{
Rajender Singh*, R.K. Aggarwal and Nupur Koul \\ Department of Microbiology, HIMS, SRHU, Dehradun, Uttarakhand, India \\ *Corresponding author:
}

\section{A B S T R A C T}

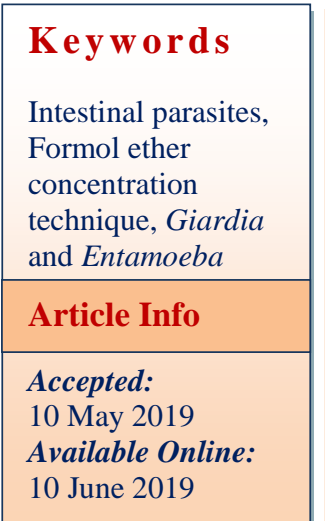

\section{Introduction}

Among various intestinal infections, parasites always contributing higher burden worldwide, especially in low socio-economic countries; and accounts for a major cause of morbidity and mortality among different high risk group (1). Age, sex, geography and other sociodemographic factors also affects the incidence and frequency of gastrointestinal parasite (2). More than 1.5 billion people, or $24 \%$ of the world's population, are infected with soiltransmitted helminth infections worldwide. Infections are widely distributed in tropical and subtropical areas, with the greatest numbers occurring in sub-Saharan Africa, the Americas, China and East Asia (3). In India, prevalence of intestinal parasites ranges from $5.56 \%$ to $90 \%$ as reported by different studies (4-9).

Intestinal parasites rarely caused death but have serious hazards on health and nutritional status of the patients $(10,11)$, along with serious impact over physical, mental \& finally socioeconomic development of children (12, 13). Helminths such as Ascaris lumbricoides, hookworm, Enterobius vermicularis and 
protozoa like Entamoeba histolytica and Giardia lamblia are some of the common intestinal parasites responsible for considerable morbidity in young and adult population (14). Himalayan Institute of Medical Sciences, Swami Rama Himalayan University, Jolly Grant, is the referral tertiary care center covering populations of major cities like Dehradun, Rishikesh, Haridwar \& hilly areas of Uttarakhand. The objective of our study to know the magnitude and sociodemographic factors affecting the prevalence of intestinal parasite among the patients attending a tertiary care center in and around Dehradun area.

\section{Materials and Methods}

Our study was hospital based study of two and a half period(Jan 2017 to April 2019) carried out in parasitology section of department of microbiology, HIMS, SRHU, Jolly Grant, situated at the outskirts of Dehradun city in Uttarakhand state.

A total number of 1078 stool sample received from the patients visited different OPD of the hospital with suspecting complaint of diarrhea or dysentery along with various complications along with relevant history. Patient under anti-helminthic drug treatment was excluded from the study group. The stool samples which were received in parasitology lab examined macroscopically for presence of adult worms or their body segments and other characteristics like color, odor, presence of blood and mucus; and also examined microscopically after preparation of iodine and normal saline wet mount of concentrated stool specimen (Formal ether concentration technique).

\section{Results and Discussion}

A total of 1078 patients visited in OPD suspected for intestinal parasites send with their stool sample to parasitology lab for routine examination. Out of which 53(4.91\%) stool samples were found positive for intestinal parasite in wet mount preparation of stool (Table 1). 43(81.13\%) males were found positive while $13(24.53 \%)$ stool were positive in females (Table 2). We also found in our study that maximum number of positive stool i.e. $12(22.64 \%)$ were found in the age group of 30-39 year old followed by 9 stool (16.98\%) from the age group of 40-49 year old (Table 3).

In our study, Giardia lamblia was found most common intestinal parasite in 20 number of stool i.e $37.74 \%$ followed by Blastocystis hominis $(18.87 \%)$ and Entamoeba histolytica (9.44\%). 5 mixed cases were also found positive in stool wet mount examination (Table 4).

In our study we also found that 36 patients $(67.9 \%)$ having positive stool were associated with mild anemia, followed by $7(13.20 \%)$, $5(9.43 \%)$ and $5(9.43 \%)$ cases were associated with moderate, severe and life threatening anemia respectively (Table 5).

Gold standard test for intestinal parasitic infection were always stool examination. Misinterpretations of intestinal parasitic infection as appendicitis and other inflammatory bowel diseases are common due to lack of knowledge of load of parasites in that particular geographical area. In our hospital based stud; we found $4.91 \%$ prevalence of intestinal parasites in and around Dehradun city which similar to other few studies from Surat, Gujrat, Rohtak, Haryana showed less than $10 \%$ prevalence rate. This low prevalence rate might be due to increasing awareness for proper hygiene, improved sanitary practices, extreme climate variations and geographical area $(4,15)$.

Our study also shows more preponderance of intestinal parasite among male patients than the female (Male: Female ratio: 3.3:1) (Table 
1) which shows similar pattern seen in other studies done at Rohtak, Haryana etc. $(16,17,18)$. This might be due to high seeking behavior among males but avoiding tendency of health facilities among females is higher.

In our study, maximum prevalence of intestinal parasite was seen in the age group of 30-39 years and least prevalence in extreme age group of above 70 years old (Table 3). However this facts goes against the other studies where maximum prevalence were seen in the age group of 0-10 years $(4,7,15,29)$. This low prevalence in our study in children might be either due to effective deworming programme or due to less OPD visits of this age group patient.

In our study, among the etiological causes of intestinal parasites; Giardia lamblia (37.74\%) was the most common isolates, followed by Blastocystis hominis $(18.87 \%)$ and Entamoeba hystolytica (9.44\%), which seems similar findings with other studies (4).

This study showed 5 cases $(9.43 \%)$ of mixed infection, which was in concordance with study at Bihar (7). Few studies showed high prevalence of mixed parasitic infection while other showed low prevalence (4).

Table.1 Prevalence of intestinal parasites in stool among suspected patients (n-1078)

\begin{tabular}{|l|l|}
\hline & Frequency \\
\hline Positive & 53 \\
\hline Negative & 1025 \\
\hline Total & 1078 \\
\hline
\end{tabular}

Table.2 Gender wise distribution of infected patients with intestinal parasites (n-53)

\begin{tabular}{|l|l|l|}
\hline & Frequency & Percentage \\
\hline Male & 43 & 81.13 \\
\hline Female & 13 & 24.53 \\
\hline Total & 53 & \\
\hline
\end{tabular}

Table.3 Age wise distribution of infected patients with intestinal parasites (n-53)

\begin{tabular}{|l|c|c|}
\hline & Frequency & Percentage \\
\hline $\mathbf{0 - 9}$ & 4 & 7.55 \\
\hline $\mathbf{1 0 - 1 9}$ & 2 & 3.77 \\
\hline $\mathbf{2 0 - 2 9}$ & 9 & 16.98 \\
\hline $\mathbf{3 0 - 3 9}$ & 12 & 22.64 \\
\hline $\mathbf{4 0 - 4 9}$ & 9 & 16.98 \\
\hline $\mathbf{5 0 - 5 9}$ & 6 & 11.32 \\
\hline $\mathbf{6 0 - 6 9}$ & 4 & 7.55 \\
\hline $\mathbf{7 0 - 7 9}$ & 1 & 1.88 \\
\hline $\mathbf{8 0 - 8 9}$ & 1 & 1.88 \\
\hline Total & 53 & \\
\hline
\end{tabular}


Table.4 Distribution of parasites isolated from the infected cases (n-53)

\begin{tabular}{|l|c|c|}
\hline & Frequency & Percentage \\
\hline Giardia & 20 & 37.74 \\
\hline Blastocystis hominis & 10 & 18.87 \\
\hline Entamoeba histolytica & 5 & 9.44 \\
\hline Entamoeba hartmanni & 2 & 3.77 \\
\hline Cryptosporidium & 2 & 3.77 \\
\hline Strongyloides & 2 & 3.77 \\
\hline H. nana & 2 & 3.77 \\
\hline Hookworm & 2 & 3.77 \\
\hline Taenia & 1 & 1.89 \\
\hline Entamoeba coli & 1 & 1.89 \\
\hline $\begin{array}{l}\text { Entamoeba hystolytica }+ \\
\text { Entamoeba coli }\end{array}$ & 1 & 1.89 \\
\hline $\begin{array}{l}\text { Entamoeba hartmanni }+ \\
\text { Blastocystis hominis }\end{array}$ & 1 & 1.89 \\
\hline $\begin{array}{l}\text { Entamoeba hystolytica }+ \\
\text { Entamoeba coli }\end{array}$ & 1 & 1.89 \\
\hline $\begin{array}{l}\text { Entamoeba coli }+ \text { Blastocystis } \\
\text { hominis }\end{array}$ & 1 & 1.89 \\
\hline Hookworm + Enterobius & 1 & 1.89 \\
\hline Total & 53 & \\
\hline
\end{tabular}

Table.5 Frequency of parasite associated with anemia (n-53)

\begin{tabular}{|l|l|l|}
\hline & Frequency & Percentage \\
\hline Mild & 36 & 67.9 \\
\hline Moderate & 7 & 13.20 \\
\hline Severe & 5 & 9.43 \\
\hline Life threatening & 5 & 9.43 \\
\hline Total & 53 & \\
\hline
\end{tabular}

In conclusion, the study done by Kotian et al., 2014 that the prevalence of intestinal parasites in the general population of hilly regions of Uttrakhand was found to be $11.62 \%$ which is in concordance with the studies from Puducherry by Ragunathan et al., and from Lathur by Davane et al., Various studies have shown that prevalence rate in India ranges from $12.5 \%$ to $66 \%$ with varying prevalence for individual parasites $[20,21,22,23]$ The wide variation in the magnitude of intestinal parasites may be due to variations in factors like sanitation, quality of drinking water supply and various climatic factors. In our study, Giardia and Entamoeba were the common isolates, which imitate the habit of defecation in open places and insufficiency of knowledge of sanitation among people. It also requires enormous importance for the exact diagnosis of parasitic infection cases as treatment protocol varies in different age group. Further research studies can be done on treatment aspects of intestinal parasites, detection of asymptomatic cases of intestinal 
parasites in the community, which helps in knowing the exact magnitude of prevalence thus helping in drafting better preventive policy much better at administration level. Research on other aspects like hygiene practices of different age group persons and different occupations that usually affects the incidence of the intestinal parasitic infection which will help in better structuring of public awareness programme.

\section{References}

1. Kang G, Mathew MS, PrasannaRajan D, Daniel JD, Mathan MM, Mathan VI, Muliyil JP. Prevalence of intestinal parasites in rural Southern Indians. Tropical Medicine \& International Health. 1998 Jan; 3(1): 70-5.

2. Ahsan-ul-Wadood BA, Rhman A, Qasim K. Frequency of intestinal parasite infestation in Children Hospital Quetta. Pak J Med Res. 2005; 44(2):87-.

3. WHO STD facts March 2019; https://www.who.int/news-room/factsheets/detail/soil-transmitted-helminthinfections

4. Patel MM, Patel PR, Gamit B, Modi J, Padsala S. Prevalence of intestinal parasites infestation in Surat city of South Gujarat: A hospital based study. Natl J Community Med. 2014; 5(3): 273-75.

5. Sethi S, Sehgal R, Malla N, Dudey ML, Mahajan RC. Changing trends of intestinal parasitic infections in Chandigarh (NG): Hospital based study. Indian Journal of Medical Microbiology. $2000 \mathrm{Jul}$ 1; 18(3): 106.

6. Rao VG, Aggrawal MC, Yadav R, Das SK, Sahare LK, Bondley MK, Minocha RK. Intestinal parasitic infections, anaemia and under nutrition among tribal adolescents of Madhya Pradesh. Indian J Community Med. 2003 Jan 26; 28(1): 26-9.
7. Kumar R, Biswas PP, Yasmin T, Sen A, Ganguly U. Prevalence of intestinal parasitic infections in patients attending a tertiary care hospital in Eastern Bihar. J Evol Med Dent Sci. 2014 Jun 16; 3(24):6740-46.

8. Patel JC. Ten year study of stool samples with particular reference to intestinal parasites. Journal of postgraduate medicine. 1986 Oct 1; 32(4):219.

9. Hegde GR, Patel JC. Prevalence of intestinal parasitic infestation in rural area. Journal of postgraduate medicine. 1986 Oct 1;32(4):225.

10Stephenson LS, Latham MC, Ottesen EA. Malnutrition and parasitic helminth infections. Parasitology. 2000 Oct; 121(S1):S23-38.

11. Stoltzfus RJ, Chway HM, Montresor A, Tielsch JM, Jape JK, Albonico M, Savioli L. Low dose daily iron supplementation improves iron status and appetite but not anemia, whereas quarterly anthelminthic treatment improves growth, appetite and anemia in Zanzibari preschool children. The Journal of nutrition. 2004 Feb 1; 134(2): 348-56.

12. Drake LJ, Jukes MC, Sternberg RJ, Bundy DA. Geohelminth infections (ascariasis, trichuriasis, and hookworm): cognitive and developmental impacts. In: Seminars in Pediatric Infectious Diseases 2000 Oct 1 (Vol. 11, No. 4, pp. 245-251). WB Saunders.

13. Guyatt H. Do intestinal nematodes affect productivity in adulthood?. Parasitology Today. 2000 Apr 1; 16(4):153-8.

14. Koneman EW, Allen SD, Janda WM, Schreckenberger PC, Winn WC, editors. (1997) Parasitology, Chapter 20. In: Color Atlas and Textbook of Diagnostic Microbiology. 5th edn. New York: JB Lipincott., pp. 1071-1076.

15. 19. Singh R., Singla P., Sharma M., Aparna, and Chaudhary, U. Prevalence 
of Intestinal Parasitic Infections in a Tertiary Care Hospital in Northern India: Five year retrospective study. Int.J.Curr.Microbiol.App.Sci (2013) 2(10): 112-117

16. Rashid MK, Joshi M, Joshi HS, Fatemi K. Prevalence of Intestinal Parasites among School Going Children In Bareilly District. National Journal of Integrated Research in Medicine. 2011 Jan 1; 2(1).

17. Manochitra K, Padukone S, Selvaratthinam PA, Parija SC. Prevalence of intestinal parasites among patients attending a tertiary care centre in South India. Int J Curr Microbiol App Sci. 2016; 5(9):1907.
20. Amin AB, Amin BM, Bhagat AP, Patel JC. Incidence of helminthiasis and protozoal infections in Bombay. Journal of the Indian Medical Association. 1979; 72(10):225-7.

21.Ramesh GN, Malla N, Raju GS, Sehgal R, Ganguly NK, Mahajan RC, Dilawari JB. Epidemiological study of parasitic infestations in lower socio-economic group in Chandigarh (north India).The Indian Journal of Medical Research. 1991 Jan; 93: 47-50.

22. Singh P, Gupta ML, Thakur TS, Vaidya NK. Intestinal parasitism in Himachal Pradesh. Indian journal of medical sciences. 1991 Aug; 45(8): 201-4.

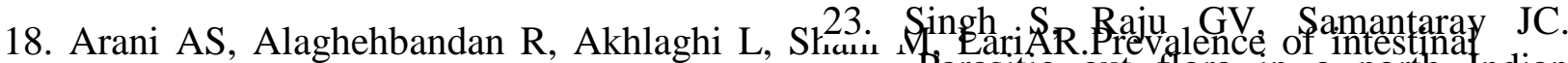
parasites in a population in south of Tehran. Iran. Prasitic gut flora in a noth Indian Tropical de São Paulo. 2008 Jun; 50(3):145-9. population with gastrointestinal

19.Bhandari B, Gupta GP, Mandowara SL. Prevalence of intestinal parasites in Udaipur. The Indian Journal of Pediatrics. 1985 May 1; 52(3): 299-302. symptoms. Tropical gastroenterology: official journal of the Digestive Diseases Foundation. 1993; 14(3): 1048.

\section{How to cite this article:}

Rajender Singh, R.K. Aggarwal and Nupur Koul. 2019. Prevalence of Intestinal Parasites at a Tertiary Care Centre at Dehradun, Uttarakhand, India. Int.J.Curr.Microbiol.App.Sci. 8(06): 932-937. doi: https://doi.org/10.20546/ijcmas.2019.806.112 